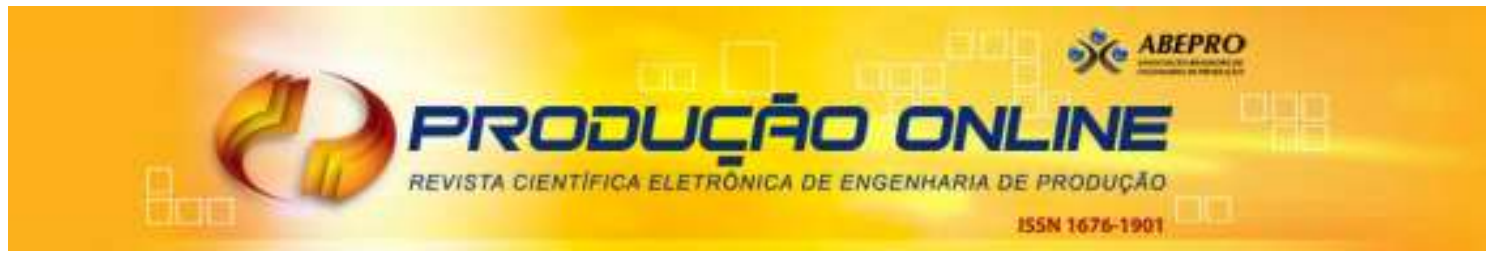

\title{
ABORDAGEM ESTRATÉGICA PARA A SELEÇÃO DE SISTEMAS ERP UTILIZANDO APOIO MULTICRITÉRIO À DECISÃO
}

\section{STRATEGIC ERP SELECTION USING MULTICRITERIA DECISION MAKING}

\author{
Carlos Francisco Simões Gomes*E-mail: cfsg1@bol.com.br \\ Helder Gomes Costa* E-mail: hgc@pq.cnpq.br \\ *Universidade Federal Fluminense (UFF), Niterói, RJ
}

\begin{abstract}
Resumo: Em um mercado que movimenta mais de 21 bilhões de dólares por ano, os Sistemas Integrados de Gestão (SIGE) são cada vez mais necessários em empresas de todos os tamanhos. Com isso, é importante adaptar-se ao mercado e escolher o sistema mais eficiente com a finalidade de obter os máximos benefícios gerados e buscar minimizar os investimentos nesses sistemas. Este trabalho utiliza os conceitos do Apoio Multicritério à Decisão, pelo uso da metodologia AHP (Analytic Hierarchy Process), para a construção de um modelo de decisão para escolha de um SIGE. É feita a escolha de um SIGE para atender as necessidades de uma empresa. Os sistemas avaliados são os fornecidos por três empresas que dominam o mercado em nível mundial. São utilizados 16 critérios de avaliação. Foi possível identificar uma alternativa dominante de acordo com as preferências do decisor.
\end{abstract}

Palavras-chave: Apoio Multicritério à Decisão (AMD). Analytic Hierarchy Process (AHP). Sistemas Integrados de Gestão (SIGE). Estratégia. Decisões multicriério.

\begin{abstract}
In a growing market that represents more than 21 billion dollars in world's economy, the Enterprise Resource Planning systems are becoming indispensable for companies of all sizes. Therefore, the companies need to adapt themselves to the market and choose the most adequate system to fit their needs in order to maximize the benefits and minimize the required investments concerning the systems. This paper utilizes Multicriteria Decision Analysis through the AHP (Analytic Hierarchy Process) to build a decision model for an ERP (Enterprise Resource Planning) choice. The model take into account 16 criteria, which are based on the literature review adapted for the needs of the company needs. The systems which were evaluated are provided by three companies that dominate the world market of ERP suppliers.
\end{abstract}

Keywords: Multicriteria Decision Support (MDS). Analytic Hierarchy Process (AHP). Enterprise Resource Planning (ERP). Strategy.

\section{INTRODUÇÃO}

Com o avanço da tecnologia, a busca por transparência e a necessidade de agilidade e controle de informações gerenciais, muitas empresas no mundo passaram a buscar soluções para esses desafios (BAZERMAN, 2004). Em 2002, nos Estados Unidos, a lei Sarbanes-Oxley definiu o aumento da transparência das empresas no que tange aos processos de negócio e contabilidade financeira para o 
mercado e, sobretudo para o governo. As empresas precisam dispor de um acesso seguro e atualizado aos seus dados e consequentemente as informações internas, além de informações do ambiente externo como fornecedores e distribuidores, em tempo real. Um dos pontos positivos em se ter um Sistema Integrado de Gestão (SIGE) é a facilidade do alinhamento do estratégico com o operacional da empresa pelo uso de informações obtidas por acesso ou relatórios de várias áreas da empresa (MENDES E FILHO, 2002).

\subsection{Contexto}

Está cada vez mais comum o alinhamento constante entre o Planejamento Estratégico e as áreas de Tecnologia da Informação (TI) dentro das empresas. Isso é fundamental para que os processos desenhados em prol de um objetivo organizacional possuam atividades automatizadas por sistemas que acabam por gerar benefícios como: busca por competitividade no plano global, preparação para o crescimento, flexibilidade e uniformização ou consolidação de dados, por exemplo. (MENDES E FILHO, 2002).

Ao final de 2008, o mercado de SIGE já movimentava 21.4 bilhões de dólares somente na venda desses sistemas, com crescimento médio de $7 \%$ ao ano desde 2000 - sobretudo com a venda em países emergentes. No caso do Brasil, segundo pesquisa SEBRAE, o crescimento estimado do setor é de $12 \%$ ao ano até 2011 , com tendência de manter-se em 2012 (SEBRAEhttp://201.2.114.147/bds/bds.nsf/B316EA7311BA4E448325753E005FA07D/\$File/NT 0003DB22.pdf)

Segundo a mesma pesquisa, pequenas e médias empresas de Software de Gestão estão ganhando espaço desse mercado, por oferecerem serviços de suporte mais acessíveis e com menores custos de manutenção.

\subsection{Justificativas}

As decisões que englobam a necessidade de um SIGE e consequentemente qual sistema implantar, não são simples para as empresas. Muitas contratam 
consultorias para realizar esse estudo e verificar qual fabricante e/ou qual software será mais adequado às necessidades operacionais daquela organização. Sob esse prisma, o ponto focal deste artigo será a utilização de uma metodologia de Apoio à Decisão Multicritério (AMD) para a criação de um modelo que satisfaça essas necessidades. Além disso, esse trabalho explorará o panorama dos SIGE desde um estudo mercadológico, passando pelo modelo de decisão até a avaliação dos benefícios ou problemas ocasionados pela e durante a implantação de um SIGE, bem como a análise de aspectos estratégicos, financeiros e operacional contemplada. Para este tipo problema podem construir-se modelos de decisão, baseados em métodos de apoio a decisão multicritério, que abordam de forma diferente o problema de priorização (DUARTE et al, 2005).

\subsection{Relevância}

Fazendo um paralelo entre o mercado de SIGE e o mercado fonográfico, pôde-se perceber que houve mudanças drásticas desde a década de 1980. No caso da indústria fonográfica, a portabilidade era ponto chave nas pesquisas das grandes corporações. Nas empresas, folhas de cálculo precisavam ser substituídas com as finalidades de aumentar a confiabilidade dos dados e padronizar processos relacionados. No mercado fonográfico, com o surgimento dos tocadores portáteis de discos compactos (CD players) posteriormente substituídos pelos MP3 players, as mídias mais antigas tornaram-se relíquia.

Nas empresas isso não é diferente. As folhas de cálculo são substituídas por versões eletrônicas, normalmente planilhas, e, posteriormente, por complexos sistemas de gestão (SANTOS; CAMPOS, 2011).

As empresas passaram a utilizar, cada vez mais, sistemas informatizados para melhorar os resultados, em razão de sua maior capacidade de processar e possibilitar o compartilhamento do conhecimento da empresa. Porém, muitos fatores contribuem para o não aproveitamento de informações: comunicação deficiente, qualificação profissional insuficiente, sistemas informatizados mal implantados, dimensionamento errado de recursos falta ou excesso de controles (VANDERLEI et al. 2009). 
Nesse aspecto, o mercado hoje busca soluções que aliem portabilidade, tecnologia, convergência e, sobretudo o verde. Segundo reportagem do Valor Econômico, algumas empresas como a $\mathrm{SAP} \AA$, por exemplo, apostam no conceito de software como serviço com seu "Carbon Impact". O gerente de sistemas sustentáveis da empresa afirma que sua aplicação está mais voltada a atividades cotidianas como viagens de funcionários e consumo de energia dentro dos escritórios e/ou área industrial.

Segundo pesquisas realizadas pela AMR Research $\AA$, pelo menos 152 empresas desenvolvem sistemas de medição das emissões de carbono. A ideia é utilizar o modelo SaaS (Software como Serviço), utilizando aplicações acessadas via web, e não a partir do computador do usuário ou empresa. As tendências de sustentabilidade estão cada vez mais presentes no desenvolvimento de TI. Tais inovações podem trazer benefícios como a redução de custos com energia elétrica, o uso racional de recursos naturais, e o reconhecimento no mercado pelos selos de sustentabilidade, entre outros.

Pesquisas realizadas pela Gartner $\AA$, em 2009, indicam que os fabricantes não podem ignorar as tendências de modernização em seus sistemas SIGE. Dentre os fatores principais, destaca-se a interface para o usuário final, que precisa seguir as tendências do conceito Web 2.0. A WEB 2.0 foi termo criado em 2004 pela empresa americana O'Reilly Media ${ }^{2}$ para designar uma segunda geração de comunidades e serviços, tendo como conceito a "Web como plataforma", permitindo a capacidade analítica integrada, além de se preocuparem não só com soluções para grandes corporações, mas também atentando para o crescimento das pequenas e médias empresas.

Existem no mercado ferramentas destinadas a facilitar o trabalho do gerente, sendo que os pacotes de SIGE ,ou em inglês ERP (Enterprise Resource Planning), são os mais utilizados (HADDAD et al., 2004).

\subsection{Objetivo}

O objetivo deste trabalho é apresentar uma modelagem baseada no Analytical Hierarchy Process (AHP), ou método multicritério para apoio à decisão, para a 
seleção de um SIGE que leve em conta aspectos estratégicos e financeiros da organização.

A escolha do método AHP para uso na empresa deveu-se aos seguintes motivos: estrutura hierárquica, que está plenamente de acordo com a cultura organizacional; e, uso da transitividade, visto que os decisores não se sentiram confortáveis com o uso de métodos da Escola Francesa.

\subsection{Estrutura do artigo}

Além desta secção de caráter introdutório este artigo é composto pela seção: 2, que apresenta revisão bibliografia do Apoio multicritierio a Decisão e o AHP; a secção 3, que discorre sobre características de um ERP/SIGE; a seção 4, que descreve a modelagem aplicada a um caso específico; e, a seção 5, que apresenta a conclusão.

\section{REVISÃO BIBLIOGRÁFICA}

Gomes e Gomes (2012) afirmam que o sucesso de um sistema de apoio à decisão (SAD) depende, em grande parte, do modo em que a estrutura de critérios é montada, levando em consideração vários pontos de vista que "representam os diferentes eixos ao longo dos quais os diversos atores do processo decisório justificam, transformam e questionam suas preferências". Esses critérios devem ser digeridos por todos os stakeholders ao longo de todo o processo de decisão. Para a análise e avaliação da maioria das decisões que precisam ser feitas nas empresas, há cenários com grande volume de variáveis e informações interligadas.

\subsection{Sobre os métodos de AMD}

Para Belton e Stewart (2004), o AMD busca pesquisar um número de alternativas, sob múltiplos critérios e objetivos em conflito, buscando gerar soluções compromisso e uma hierarquização das alternativas, de acordo com o grau de atração destas para o tomador de decisão. 
No modelo para tomada de decisão estão compreendidos os seguintes componentes: critérios, pesos e as classificações que são dadas para cada alternativa, em cada critério. Pressupondo o conhecimento das preferências dos atores da decisão e a qualidade da avaliação, pode-se admitir que uma ação seja tão boa, melhor ou pior que outra, ou seja, hierarquizar as alternativas (GOMES, MAIA, 2012).

Segundo Bouyssou (1986) uma abordagem multicritério apresenta as seguintes vantagens:

- Torna viável a construção de uma base para o diálogo entre analistas e decisores, que fazem uso de diversos pontos de vista comuns;

- Provê facilidade em tratar incorporar incertezas dos dados sobre cada ponto de vista;

- Permite entender cada alternativa como um compromisso entre objetivos em conflito. Este argumento destaca o fato de que raramente será encontrada uma situação em que exista uma alternativa superior às restantes sobre todos os pontos de vista.

Conforme descrito em textos como Roy e Boyssou (1993) e em Gomes e Gomes (2012), no contexto do apoio à decisão, o resultado pretendido em determinado problema pode ser identificado entre quatro tipos de problemática de referência, descritas a seguir:

a) Problemática P.a - tem como objetivo esclarecer a decisão pela escolha de um subconjunto tão restrito quanto possível, de alternativas, tendo em consideração a escolha final de uma única ação. Esse conjunto conterá as "melhores ações" ou as ações "satisfatórias". O resultado pretendido é, portanto, uma escolha;

b) Problemática P. $\beta$ - tem como objetivo esclarecer a decisão por uma triagem resultante da alocação de cada alternativa a uma categoria (ou classe). As diferentes categorias são definidas a priori com base em normas aplicáveis ao conjunto de ações. O resultado pretendido é, portanto um procedimento de classificação; 
c) Problemática P.y - tem como objetivo esclarecer a decisão por um arranjo obtido pelo reagrupamento de todas ou parte (as alternativas mais satisfatórias) das ações em classes de equivalência. Essas classes são ordenadas de modo completo ou parcial, conforme as preferências do(s) decisore(s). O resultado pretendido é um procedimento de ordenação;

d) Problemática P.ঠ - tem como objetivo esclarecer a decisão por uma descrição, em linguagem apropriada, das ações e de suas consequências. O resultado pretendido é, portanto, uma descrição ou um procedimento cognitivo.

O problema abordado neste artigo é do tipo P.a, pois trata-se de um problema de escolha de uma opção dentre um conjunto finito e discreto de alternativas.

\subsection{Apoio Multicritério à Decisão (AMD): Método AHP}

Métodos que apoiam a tomada de decisão com múltiplos critérios, também conhecidos como Apoio Multicritério à Decisão (AMD) ou Multiple Criteria Decision Making (MCDM), possuem características particulares e trazem ao decisor uma nova discussão: qual deles é mais recomendado para determinada situação. Dentre os métodos mais difundidos destaca-se o MAUT - Multiattribute Utility Theory, que é considerado um método simplificado, porém fácil de ser aplicado. Além deste, podese destacar o método mais difundido no meio acadêmico, o AHP. Este método foi desenvolvido por Thomas Saaty, no início dos anos 70, sendo aperfeiçoado ao longo de suas aplicações (SAATY, 2010a). O AHP é uma importante ferramenta para o auxílio à tomada de decisão, pois consegue envolver em sua modelagem tanto aspectos quantitativos como qualitativos, estruturando em forma de árvore (hierarquia) uma decisão complexa. Tem ampla aplicação auxiliando na solução de diferentes problemas, (SOUZA et al., 2010).

Tomada de decisão em engenharia, porém não só em engenharia, está se tornando cada vez mais complexo devido ao grande número de alternativas e várias metas conflitantes. Poderosos sistemas de apoio à decisão especialista alimentados por software adequado são cada vez mais necessário (BENìTEZ et al., 2012). Dentre os métodos existentes, o processo de análise hierárquica AHP é, possivelmente, o mais conhecido e mais usado. O método é abundantemente 
exemplificado na literatura (DIAS et al., 2011) e, segundo Filho et al, (2010), é aplicado em ambientes cujas decisões possuem elevado grau de importância.

A aplicação, da AHP, pode ser resumida por estruturar uma hierarquia, começando pelo objetivo principal, passando pelos critérios de avaliação e, finalmente chegando ao mais baixo nível da hierarquia, geralmente uma relação de alternativas para cada um dos critérios; e por fim estabelecer as prioridades (COMERLATO et al., 2013).

O presente estudo utiliza o AHP, reportado em Saaty e Shang (2007), pois os problemas de TI normalmente não são estruturados com decisões estratégicas e múltiplos critérios definidos tanto quantitativa quanto qualitativamente. No AHP, a organização dos dados acaba por facilitar a compreensão e avaliação do problema de decisão, partindo-se do objetivo, descendo hierarquicamente dos critérios para os subcritérios em prol da resolução do problema (FIGUEIRA et al., 2005). No entanto, o uso do AHP (assim como o de outros métodos de apoio à decisão) deve ser elaborado de forma científica e cuidadosa. Caso contrário, pode-se tornar uma "máquina de gerar números" sem um compromisso maior com o auxílio à solução do problema em tela.

A coleta de dados no AHP deve ser efetuada com base na escala de Saaty ou em variações validadas da mesma. Belton e Gear (1982) apresentam uma variação do Método AHP, denotada por AHP-BG. Esta variação adota uma escala não linear associada à Escala de Julgamentos subjetivos de Saaty, que adota uma escala linear.

O problema do uso inadequado de escalas é abordado em Costa (2006), que reporta que em algumas situações, em função da disponibilidade de avaliações quantitativas (esta é uma situação comum no caso de emprego de critérios financeiros), é usual a adoção de "regras de conversão" do tipo:

"Caso a alternativa $X$ tenha um custo três vezes menor do que o da alternativa $Y$, então associa-se diretamente o valor 3 ao elemento $a_{x y}$ na matriz de julgamentos do AHP."

Costa (2006) destaca que isso é um equívoco, caso seja feito sem se verificar o conceito ou julgamento associado ao número três, pois está se assumindo que a alternativa $\mathrm{x}$ é fracamente preferível ou superior a alternativa $\mathrm{y}$. 
Note-se que esta associação de conceitos e percepções é feita da mesma forma, mesmo para situações muito distintas, tais como:

$x=R \$ 1,00 ; e, y=R \$ 3,00$;

$x=R \$ 1.000,000,00 ; e, y=R \$ 3.000,000,00$;

Esta associação feita de forma equivocada e indiscriminada desconsidera o real significado do conceito ou julgamento de valor. Assim, observa-se a importância de se fazer os julgamentos inicialmente em uma escala verbal, para posteriormente, converte-los em uma escala numérica - como a Escala de Saaty.

Segundo Costa (2006) outro cuidado a ser tomado é a utilização do AHP para definição de "rankings" ou escolhas sequenciais:

"Ao se processar o AHP, o mesmo resulta em um vetor de prioridades que nos permite uma ordenação ("ranking”) das alternativas. Por exemplo, dado um conjunto de alternativas $\underline{A}=\left(A_{1}, A_{2}, A_{3}, A_{4}, A_{5}\right)$. Com base em julgamentos de valor, o AHP pode atribuir às alternativas as seguintes "prioridades":

$A_{1}=0,35 ; A_{2}=0,25 ; A_{3}=0,20 ; A_{4}=0,15 ; A_{5}=0,05$.

Com base nestas prioridades pode-se estabelecer a ordenação das alternativas.

$$
A_{1}=1^{a} ; A_{2}=2^{a} . ; A_{3}=3^{a} . ; A_{4}=4^{a} . ; A_{5}=5^{a} \text {. }
$$

Considere que este seja um problema de seleção de um funcionário para contratar um funcionário para o preenchimento de uma vaga ou posto de trabalho em uma organização. Neste caso, o funcionário denotado pela alternativa $A_{1}$ é convocado para assumir a vaga. Suponha que este funcionário desista de assumir esta vaga. O que acontece? Em geral a resposta a esta pergunta é a seguinte: convoca-se o candidato $A_{2}$, que é o segundo colocado indicado pela ordenação (priorização) gerada a partir do vetor de prioridades. O que acontece é que o problema mudou com a saída do candidato $A_{1}$ do conjunto de alternativas. Neste caso, o algoritmo de priorização deveria ser novamente "rodado", retirando as informações referentes ao candidato $A_{1}$ e resguardando as demais entradas de dados. Nesta nova configuração, pode ser que a alternativa $A_{2}$ não seja considerada a que melhor atende as necessidades do problema (esta situação "paradoxal" pode ocorrer no AHP). 
Situação semelhante ocorre se após a contratação do funcionário A1, ocorrer mais uma vaga. Ou seja: No AHP, o resultado é muito sensível ao conjunto das alternativas considerado (SAATY, 2010b). O AHP não é um método diretamente indicado para a ordenação (apesar de se observar na literatura aplicações do mesmo para este fim). É sim uma importante ferramenta de escolha e, mais ainda, de identificação da alocação e distribuição de prioridades. "Por fim, ressalta-se que esta "armadilha" está relacionada ao problema de reversão de ordem associado.".

Costa (2006) destaca que "em diversas situações, alguns critérios (por exemplo: o critério preço) apresentam uma importância muito alta ou extrema em relação aos demais critérios. Isto aumenta a possibilidade de se ter uma "grande" inconsistência na modelagem. Em alguns destes casos poderiam ser excluídos da hierarquia de priorização de forma a reduzir a inconsistência? Pode-se sugerir uma modelagem híbrida na qual os critérios com importância muito alta sejam utilizados em etapa prévia ao AHP, mais especificamente: na definição das alternativas viáveis. Estes critérios seriam "critérios qualificadores" das alternativas, e os demais seriam "critérios de ordenação ou de priorização". Por exemplo: na compra de um carro, o preço é um fator determinante na definição das alternativas viáveis (ou seja: é um importante critério de qualificação). Mais ainda, em geral, para este problema, observa-se que as alternativas viáveis não apresentam grandes preferências (têm desempenho semelhante) à luz deste critério. Neste tipo de situação o preço atua como um critério de qualificação e não tem muita influencia como critério de priorização. Manter um critério com esta característica na hierarquia agrega pouco valor à priorização e pode trazer como efeito colateral problemas de inconsistência na definição nas prioridades dos critérios.".

\section{SISTEMAS INTEGRADOS DE GESTÃO (SIGE)}

Sistema ERP ou SIGE são sistemas de informação que integram todos os dados e processos de uma organização em um único sistema. A integração pode ser vista sob a perspectiva funcional (sistemas de: finanças, contabilidade, recursos humanos, fabricação, marketing, vendas, compras, etc) e sob a perspectiva sistêmica (sistema de processamento de transações, sistemas de informações 
gerenciais, sistemas de apoio à decisão, etc.). ERP é assim um sistema de gestão empresarial que gerencia as informações relativas aos processos operacionais, administrativos e gerenciais das empresas. (GOMES; RIBEIRO, 2014)

Os sistemas ERP também são definidos como um conjunto de programas (software) de computador para maximizar ganhos produtivos e financeiros, minimizando retrabalhos e custos; alguns autores utilizam em português o termo PGI (Programas de Gestão Integrada); e estes fornecem aos gestores e executivos informações precisas para tomada de decisão melhorando os negócios da empresa (RIBEIRO; RIBEIRO, 2004). O uso do SIGE pode afetar a organização em todas as suas áreas (LIMA, 2000), sendo essa influência resultante da quantidade de módulos adotados pela empresa. Sob o enfoque de negócios, Buckhout; Frey e Nemec (1999) conceituam o ERP como um software de planejamento dos recursos empresariais que integra as diferentes funções da empresa, para criar operações mais eficientes. Um ERP é um sistema de informações para planejar e integrar todos os subsistemas de uma empresa, incluindo a compra, produção, vendas e finanças. Adotando tal quadro abrangente pode resultar em grande economia de custos e homens-hora (GÜRBÜZ et al., 2012).

O objetivo de um Sistema ERP é centralizar as informações e gerir o seu fluxo durante todo processo de desenvolvimento da atividade empresarial, integrando os setores da organização e possibilitando aos gestores acesso ágil, eficiente e confiável às informações gerenciais, dando suporte à tomada de decisões em todos os níveis do negócio. São construídos sobre um banco de dados centralizado, denominado Data Warehouse, sendo estes parcionados em Data Mart (DM). Na figura 1 observa-se um exemplo de DW com DMs.

Os sistemas ERP consolidam todas as operações de uma empresa em um único sistema, Os sistemas ERP abrangem cada passo da operação, desde as compras, provisões, planejamento, manufatura, formação de preços, contas a pagar e receber, processos contábeis, controle de estoque, administração de contratos, venda de serviços e todos os níveis de comércio varejista ou atacado, passando pela gestão eficaz dos relacionamentos com clientes e fornecedores, pós-venda, análise de resultados e muitos outros fatores personalizados, altamente adaptáveis a qualquer empresa, em qualquer ramo de negócios (PORTAL DO ERP, 2012). 
Figura 1 - Representação da associação entre Data Warehouse (DW) e Data Mart (DM).

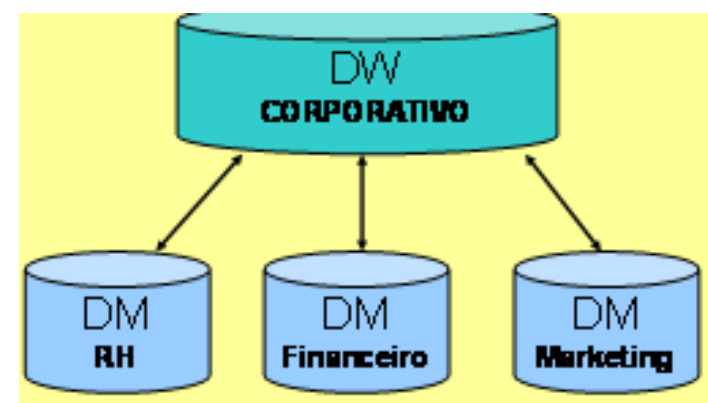

O uso de um Sistema ERP em uma empresa dá a seus gestores o controle total sobre a empresa, auxiliando na tomada de decisões e fornecendo todas as informações vitais de maneira acessível e clara.

Os Principais objetivos da implantação de um sistema ERP são (Portal do ERP, 2012):

- Automatização de tarefas manuais

- Otimização de processos;

- Controle sobre as operações da empresa;

- Disponibilidade imediata de informações seguras;

- Redução de custos;

- Redução dos riscos da atividade empresarial;

Obtenção de informações e resultados que auxiliem na tomada de decisões e permitam total visibilidade do desempenho das áreas da empresa

Os fabricantes de ERP buscam fazer sistemas a partir da incorporação de modelos de processos obtidos pela experiência acumulada de fornecedores, consultorias e pesquisas em geral. Mendes e Filho (2002) apresentou um quadro com as principais características desejadas em SIGE's e a relação de autores correspondentes. A pesquisa feita buscou adaptar e atualizar as definições apresentadas na Tabela 1, sendo que os autores de 15 a 18 foram agregados à tabela original de Mendes e Filho (2002). Conforme reportado em Farbey et al. (1992), há um grande número de estudos envolvendo métodos quantitativos e qualitativos para apoio à decisão multicritério para auxiliar na escolha por um SIGE e 
outras ferramentas de Tecnologia da Informação Entretanto, muitas companhias utilizam apenas modelos financeiros para esse fim).

O ERP é constituído por vários "módulos" que suportam todas as áreas de uma empresa. Por se tratar de sistema genérico, independe do fato de a empresa que vai adotá-lo ser de manufatura ou prestadora de serviços. A abrangência do sistema é limitada pela empresa, podendo estar atrelada a vários motivos, como: custo de implantação dos módulos, possibilidade de integração de sistemas menores ao ERP. A integração da empresa, facilitada pelo uso de ERP, é decorrente de alguns fatores, como: possibilidade de a empresa operar com um único sistema de informação que atenda a todas as suas áreas; armazenamento dos dados em um banco de dados único e centralizado; e orientação a processos.

Tabela 1 - Quadro síntese da revisão bibliográfica: Características esperadas em SIGE

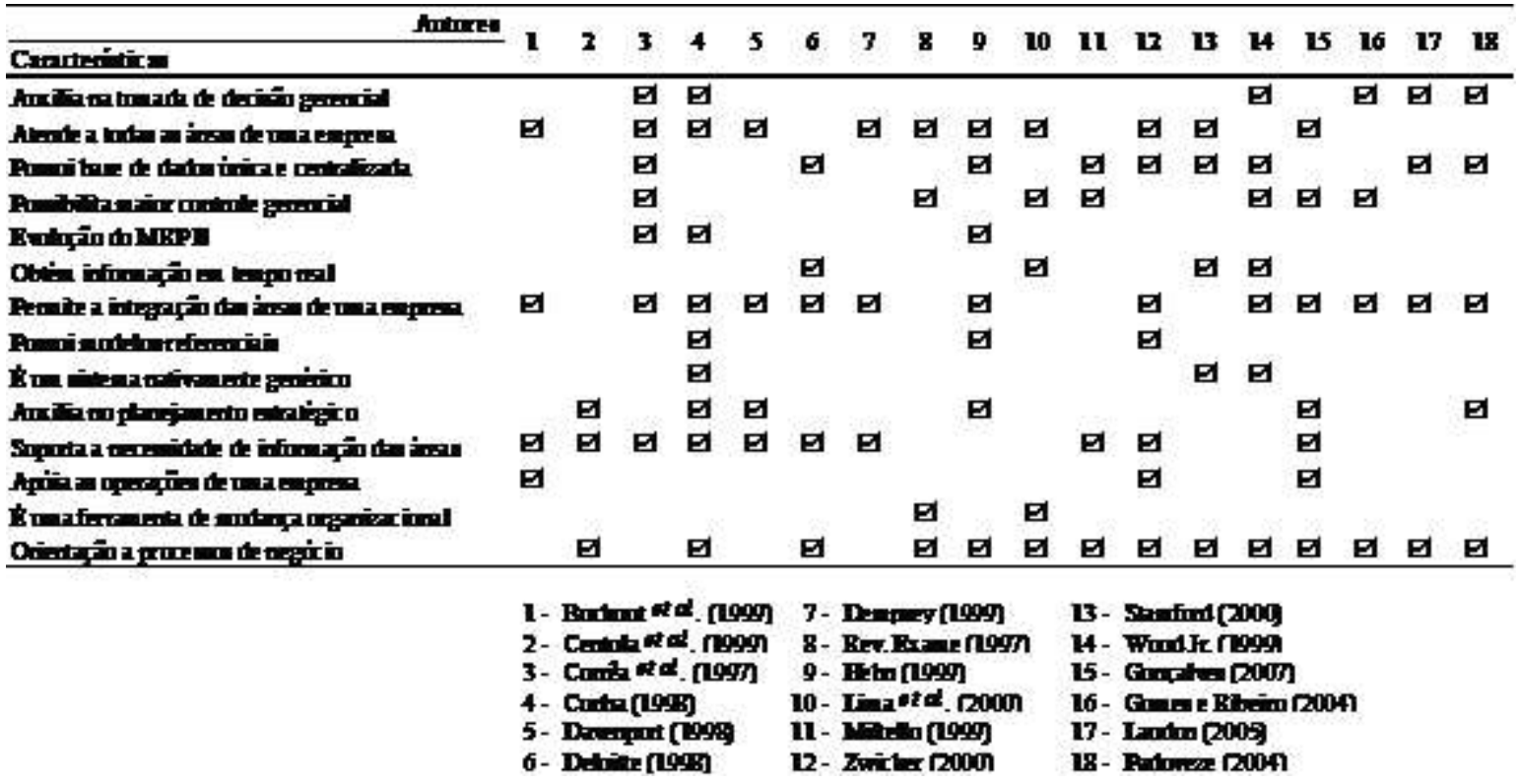

Os processos, implementados no sistema, não se restringem a uma área ou departamento, quebrando barreiras impostas pelas estruturas departamentais e outros. (MENDES; FILHO, 2002)

O ERP se diferencia dos demais sistemas pela integração das informações da empresa, por meio do uso de um banco de dados único para toda a organização. Ele é composto de módulos integrados que atendem a cada área funcional ou 
processo, como Finanças, Produção, Custos, Vendas, RH etc. (SACCOL et al., 2004).

\subsection{Aspectos gerais da implantação de um ERP}

A implantação de um ERP em uma organização é um assunto crítico, pois envolvem normalmente investimentos substanciais, prazos significativos além da escolha do sistema mais adequado e do envolvimento dos stakeholders com a ferramenta (COLANGELO, 2001).

Segundo Gattiker (2007), pode-se analisar a implantação de um ERP desde o Estudo da necessidade até o Pós-Implantação em sete etapas essenciais, explicitados a seguir.

- No Planejamento Estratégico de uma empresa é percebida a necessidade de um SIGE, por questões de confiabilidade de dados, gestão da informação, automatização de alguns processos entre outros fatores possibilitados com a operação de um SIGE na organização (MENDES; FILHO, 2002).

- Em seguida, deve-se definir a estratégia a ser utilizada para a escolha do sistema mais adequado (GOMES; MENAHEM, 2012). Algumas empresas contratam consultores especializados e acabam por terceirizar essa tarefa. Entretanto, outras empresas pesquisam e solicitam visitas dos fabricantes com a finalidade de descobrir a melhor solução, normalmente com aspectos financeiros, tecnológicos / funcionais e de flexibilidade (SANTOS; CAMPOS, 2011)

- A próxima etapa, a de Análise da Decisão, tem como objetivo a escolha dentre as alternativas pleiteadas nas fases anteriores. Há diversos modelos de decisão multicritério, estudos de viabilidade de projetos, análises de cenários, entretanto algumas organizações preferem contratar especialistas para essa escolha, e normalmente acabam por incorrer em custos que poderiam ser evitados. 
- O planejamento de implantação tem como objetivo principal o estudo para alocação dos recursos financeiros, temporais e humanos que participarão diretamente durante a implantação. Essa etapa inclui a possível contratação de uma consultoria especializada em implantação de Sistemas Integrados de Gestão, mobilização das equipes funcionais, alocação de espaço físico, cronogramas, planejamento de aquisição de Hardware e negociação com todos os fornecedores envolvidos. Em muitos casos, os Projetos de Implantação são divididos em cinco etapas: Análise de Processos, Desenho da Solução, Construção (configuração) da Solução, Testes Integrados e Implantação (go-live). Esses projetos duram, na maioria dos casos, de 6 a 24 meses (COLÂNGELO, 2001). Em paralelo, nas últimas etapas, normalmente os usuários finais, que não estão participando diretamente do projeto de implantação, são treinados para o uso da ferramenta em questão.

- As etapas posteriores ao projeto de Implantação, a Entrada em Produção e seus ajustes e a Melhoria Contínua são muito relacionadas, porém não totalmente. A primeira dá preferência aos ajustes logo após a implantação, que em muitos casos são relacionados à atribuição de funções, ou seja, a maioria dos problemas pós-implantação é ligada ao controle de acesso por parte dos usuários finais.

- A Melhoria Contínua é o ponto chave da manutenção otimizada de um Sistema Integrado de Gestão. O constante treinamento dos usuários, aperfeiçoamento da ferramenta e o uso dos recursos disponibilizados pelo sistema são cruciais para uma posterior avaliação holística da implantação do sistema em uma organização.

\subsection{Fatores críticos de sucesso}

Dentre os desafios mais comuns em implantação de sistemas desse porte, pode-se afirmar que o apoio da direção e o envolvimento do usuário com a ferramenta durante o processo como um todo são pontos cruciais que denotam o sucesso de uma implantação. Entretanto, o estudo da necessidade normalmente 
não é realizado corretamente nas empresas, o que pode fazer com que o investimento traga menos benefícios do que o previsto.

Além disso, deve ser disponibilizado um treinamento uniforme envolvendo todos os usuários que terão acesso à ferramenta pós go-live. Tal treinamento pode ser feito por multiplicadores, ou usuários-chave. Essa técnica é utilizada por algumas empresas de consultoria e consiste no fato de os futuros treinadores participem do projeto com a finalidade de adquirir conhecimento que será passado aos usuários finais em seus departamentos organizacionais.

Outro ponto interessante de ser analisado é o planejamento do projeto. Como qualquer planejamento, devem ser respeitadas as expectativas por resultados realistas, em outras palavras, após as análises, o planejado deve estar o mais aderente possível do realizado. A participação de especialistas no planejamento é crucial, assim como uma boa frente de Gerenciamento de Projetos (PMO). A empresa precisa se adequar ao sistema. Caso isso não ocorra, o projeto de implantação será repleto de gaps - ou "lacunas" - que representam desenvolvimentos ou inadequações. Essa falta de aderência é muito comum, visto que os sistemas possuem funções padronizadas, e cada empresa possui um modo de operação.

\section{ESTUDO DE CASO}

A abordagem metodológica aplicada a presente pesquisa, baseia-se em um estudo de caso no qual é efetuada a construção de um modelo de apoio à decisão para a seleção de um sistema ERP. Esta abordagem está estruturada nas seguintes etapas:

- Revisão bibliográfica buscando identificar critérios previamente adotados para a seleção de sistemas ERP.

- Elaboração de árvore de critérios, incluindo a validação da mesma por especialistas da organização.

- Identificação das alternativas viáveis. 
- Coleta de julgamentos paritários de valor a respeito da importância relativa dos critérios e do desempenho das alternativas.

- Aplicação do algoritmo de priorização do AHP aos dados coletados e análise dos resultados obtidos.

\subsection{Definição do problema}

O estudo busca obter um modelo de seleção de um SIGE. Sabe-se que cada organização possui um determinado tipo de necessidade e, por isso, é prudente afirmar que o atual modelo se trata da percepção de seis especialistas acerca dos critérios a serem analisados.

A empresa em que foi feita o estudo de caso decidiu implementar um ERP/SIGE com o propósito de obter as vantagens descritas anteriormente, bem como integrar os Banco de Dados da mesma, e otimizar os seus processos. Foi criado um grupo, com pessoas da empresa e fora da mesma, aonde participavam seis especialistas em SIGE.

O processo consistiu uma ampla revisão bibliográfica sobre o tema, e posterior apresentação aos especialistas dos resultados obtidos.

As alternativas analisadas são soluções propostas pelos três maiores fabricantes de SIGE, em atuação no mercado brasileiro. Segundo os dados de Belli (2010), Brodbeck (2010), Da Costa et al (2010) e Lima (2000), juntas elas somavam $80 \%$ da fatia de mercado brasileiro desde 2009. Estas empresas são aqui denominadas por Fabricante A, Fabricante B e Fabricante C.

\subsection{Aplicação do AHP}

A pesquisa efetuada, e posterior validação pelos especialistas, gerou a Figura 2, a árvore de critérios contempla cinco critérios no primeiro nível e dezessete critérios no segundo nível, conforme demonstrado na Figura 2. O quadro 1 apresenta uma descrição dos critérios e subcritérios.

Salienta-se que a aplicação do processo de gestão consiste em levantar as avaliações das atividades para todos os novos critérios (MIRANDA et al, 2003). 
Com base nesta árvore de critérios da Figura 2, foi elaborado um questionário para apoiar a coleta de julgamentos junto aos especialistas. Foram coletados julgamentos quanto à importância relativa dos critérios e subcritérios; e, também, quanto ao desempenho das alternativas. Este estudo buscou identificar a importância dos critérios, bem como a pontuação/classificação de cada alternativa em cada critério.

Ramos (2007) salienta que os atores de um processo decisório são definidos de acordo com a sua relação com o problema identificado. Neste caso a equipe com os seis especialistas selecionados pela empresa.

Figura 2 - Estrutura de Critérios do Estudo

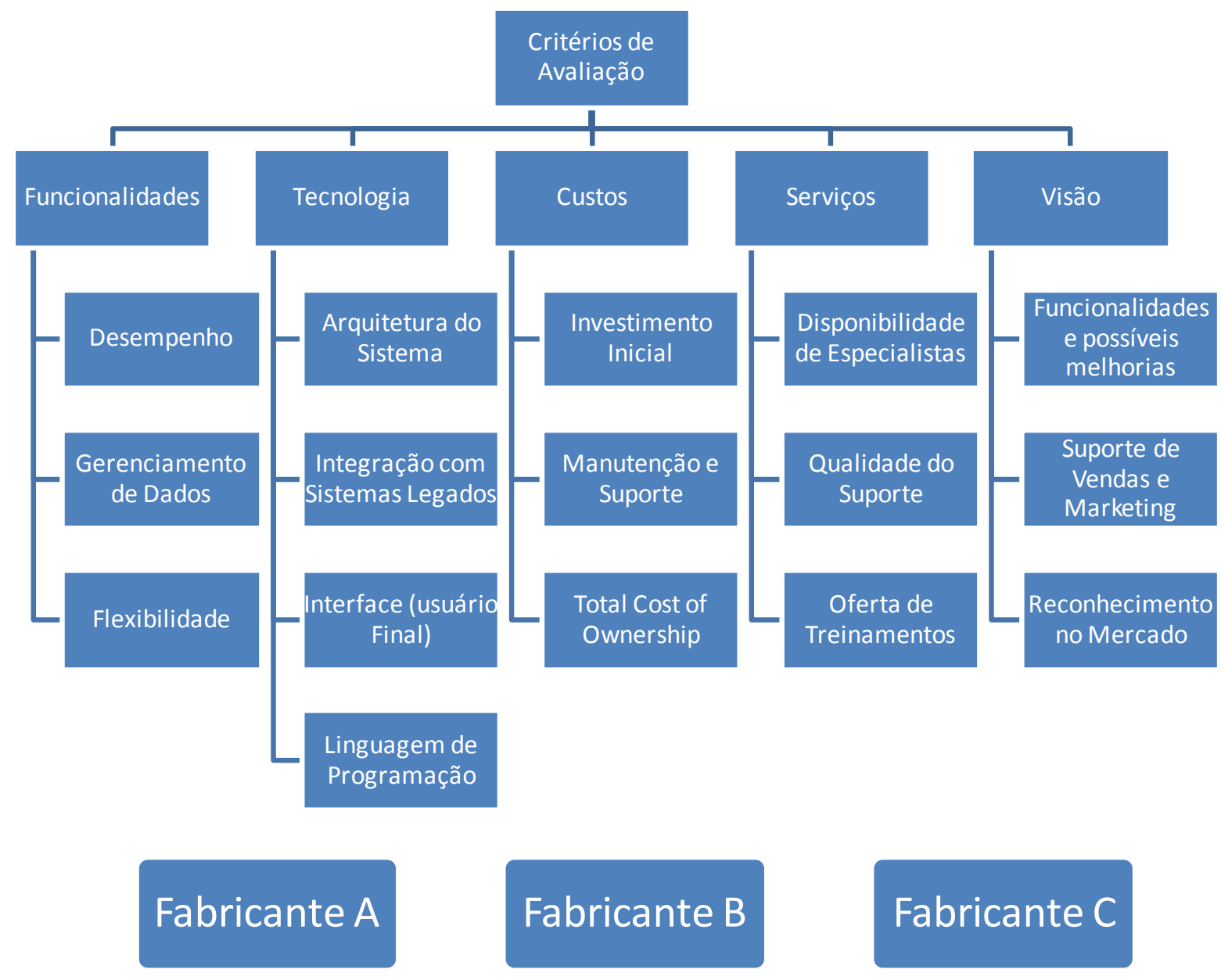

Revista Produção Online, Florianópolis, SC, v.13, n. 2, p. 1060-1088, abr./jun. 2013. 
Quadro 1 - Descrição dos Critérios e Subcritérios

\begin{tabular}{|c|c|}
\hline Critério & Descrição \\
\hline Funcionalidades & $\begin{array}{l}\text { Avalia o ERP no que diz respeito às suas funcionalidades padrão } \\
\text { e sem desenvolvimentos. }\end{array}$ \\
\hline Desempenho & $\begin{array}{l}\text { Avalia o comportamento do sistema em relação à rapidez de resposta } \\
\text { no uso cotidiano. }\end{array}$ \\
\hline $\begin{array}{l}\text { Gerenciamento } \\
\text { Dados }\end{array}$ & $\begin{array}{l}\text { Avalia a capacidade de inclusão e extração de dados com velocidade } \\
\text { e precisão. }\end{array}$ \\
\hline Flexibilidade & $\begin{array}{l}\text { Avalia a flexibilidade na configuração dos módulos, a fim de evitar } \\
\text { desenvolvimentos no sistema. }\end{array}$ \\
\hline Tecnologia & $\begin{array}{l}\text { Avalia a complexidade tecnológica e a atualização do sistema } \\
\text { frente ao mercado e suas evoluções. }\end{array}$ \\
\hline $\begin{array}{l}\text { Arquitetura } \\
\text { Sistema }\end{array}$ & Avalia a compatibilidade com diferentes frameworks. \\
\hline $\begin{array}{l}\text { Integração com } \\
\text { Sistemas Legados }\end{array}$ & $\begin{array}{l}\text { Avalia a possível integração com sistemas legados a fim de facilitar a } \\
\text { conversão inicial de dados e/ou extrair informações para outros } \\
\text { sistemas em operação. }\end{array}$ \\
\hline $\begin{array}{ll}\text { Interface } & \text { (Usuário } \\
\text { Final) } & \end{array}$ & $\begin{array}{l}\text { Avalia a interface operada por usuários finais tal como a possibilidade } \\
\text { ou não de ferramentas do sistema via internet. }\end{array}$ \\
\hline $\begin{array}{ll}\text { Linguagem } & \text { de } \\
\text { Programação } & \end{array}$ & $\begin{array}{l}\text { Avalia a qualidade e complexidade da linguagem de programação por } \\
\text { trás do sistema. }\end{array}$ \\
\hline Custos & $\begin{array}{l}\text { Avalia toda a cadeia de custos envolvidos no investimento em um } \\
\text { ERP. }\end{array}$ \\
\hline Investimento Inicial & $\begin{array}{l}\text { Avalia o montante necessário para a implantação do sistema em uma } \\
\text { empresa contemplando: Consultoria/Implantação, Software e } \\
\text { Hardware. }\end{array}$ \\
\hline $\begin{array}{l}\text { Manutenção } \\
\text { Suporte }\end{array}$ & Avalia o custo para a manutenção dos sistemas analisados. \\
\hline $\begin{array}{l}\text { Total Cost } \\
\text { Ownership }\end{array}$ & $\begin{array}{l}\text { Avalia o custo total de propriedade dos sistemas em questão. O Total } \\
\text { Cost of Ownership(TCO), analisa tanto aspectos financeiros quanto } \\
\text { econômicos. }\end{array}$ \\
\hline Serviços & Avalia o nível de serviço dos sistemas analisados. \\
\hline $\begin{array}{l}\text { Disponibilidade } \\
\text { Especialistas }\end{array}$ & 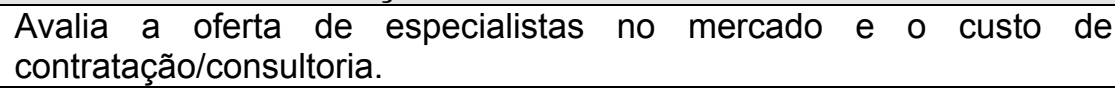 \\
\hline Qualidade do Suporte & $\begin{array}{l}\text { Avalia a qualidade do suporte prestado pelos fabricantes pré e pós- } \\
\text { implantação. }\end{array}$ \\
\hline $\begin{array}{l}\text { Oferta } \\
\text { Treinamentos }\end{array}$ & $\begin{array}{l}\text { Avalia a oferta de treinamento para a ferramenta disponibilizado pelos } \\
\text { fabricantes. }\end{array}$ \\
\hline Visão & Avalia questões mercadológicas e estratégicas. \\
\hline $\begin{array}{l}\text { Funcionalidades e } \\
\text { Possíveis Melhorias }\end{array}$ & $\begin{array}{l}\text { Avalia a possibilidade de atualização dos sistemas tal como possíveis } \\
\text { adequações/desenvolvimentos nos sistemas implantados. }\end{array}$ \\
\hline Suporte de Vendas & $\begin{array}{l}\text { Avalia o suporte de vendas para possíveis negociações de outros } \\
\text { produtos. }\end{array}$ \\
\hline $\begin{array}{l}\text { Reconhecimento no } \\
\text { Mercado }\end{array}$ & $\begin{array}{l}\text { Avalia o reconhecimento do fabricante no mercado a fim de atestar } \\
\text { confiabilidade. }\end{array}$ \\
\hline
\end{tabular}

Com o suporte do questionário os seis especialistas em SIGE foram consultados de três formas: entrevista pessoal; emails enviados; e, email e entrevista. Estes especialistas, com média de idade em torno dos trinta e quatro anos, tinham nove anos de experiência com pelo menos dois dos sistemas analisados como alternativas, e conhecimento teórico do outro sistema. Quatro dos 
entrevistados trabalhavam, à época da pesquisa, em empresas de consultoria na implantação dos SIGEs analisados. Os outros dois especialistas trabalhavam diretamente com o(s) fabricante(s). Cinco dos entrevistados possuem diploma de graduação em: Engenharia de Produção, Engenharia Elétrica ou Sistemas de Informação; ao passo que dois possuem pós-graduação em Gestão Empresarial.

Alguns avaliadores relataram dificuldades no preenchimento do questionário, o que gerou a necessidade de ampliar o número de emails, ocorrer novas entrevistas e, alguns casos, contato por telefone.

Os dados coletados foram tabulados e utilizados para cálculo no AHP, gerando os seguintes resultados:

A Figura 3 apresenta os pesos dos critérios e, também, dos subcritérios considerados na árvore de critérios. Estes pesos foram obtidos a partir da aplicação do algoritmo de priorização do AHP aos julgamentos coletados junto aos especialistas.

Combinando os resultados apresentados na Figura 3, a pesquisa também permitiu identificar o grau de prioridade de cada um dos Fatores Críticos de Sucesso, os quais estão reportados na Tabela como pode ser observado na Tabela 3. Com base nos resultados apresentados na tabela 2 é possível concluir que os Fatores Críticos de Sucesso considerados como mais importantes são aqueles associados à Funcionalidade do SIGE. 
Figura 3 - Pesos dos critérios e subcritérios

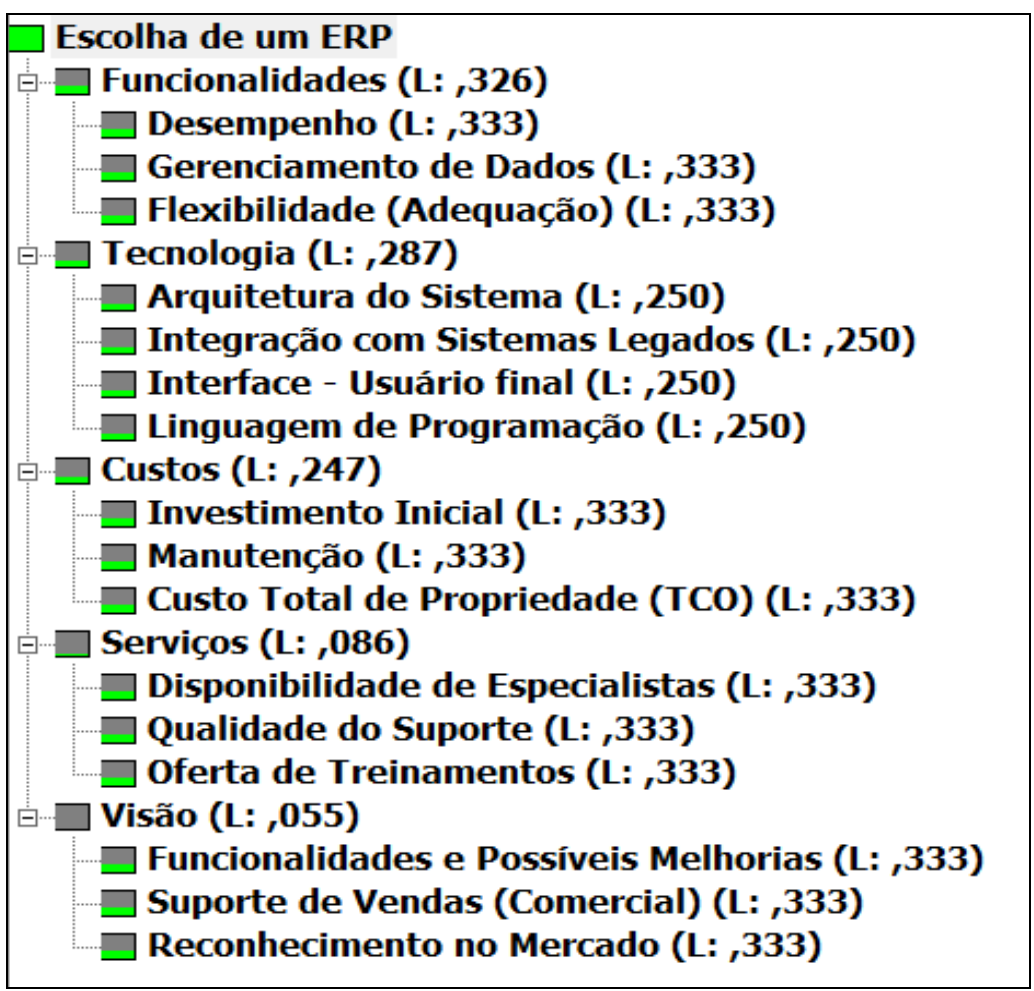

Tabela 2 - Peso dos Critérios

\begin{tabular}{lll}
\hline Critério & Fator Crítico de Sucesso & Grau de Prioridade \\
\hline Funcionalidades & Desempenho & 0,109 \\
& Gerenciamento de Dados & 0,109 \\
Tecnologia & Flexibilidade & 0,109 \\
& Arquitetura do Sistema & 0,072 \\
& Integração com Sistemas Legados & 0,072 \\
& Interface (Usuário Final) & 0,072 \\
Custos & Linguagem de Programação & 0,072 \\
& Investimento Inicial & 0,082 \\
\multirow{4}{*}{ Serviços } & Manutenção e Suporte & 0,082 \\
& Total Cost of Ownership & 0,082 \\
\multirow{2}{*}{ Visão } & Disponibilidade de Especialistas & 0,029 \\
& Qualidade do Suporte & 0,029 \\
& Oferta de Treinamentos & 0,029 \\
& Funcionalidades e Possíveis Melhorias & 0,018 \\
& Suporte de Vendas & 0,018 \\
& Reconhecimento no Mercado & 0018 \\
\hline
\end{tabular}

Após montar, as matrizes de comparação das alternativas em relação aos critérios e distribuir os pesos dos critérios, houve a combinação normalizada dos resultados obtidos na análise dos questionários. O Fabricante B obteve a pontuação de 0,353 , enquanto os Fabricantes $A$ e $C$ obtiveram 0,341 e 0,306 respectivamente. 
Pode-se afirmar que a diferença entre os fabricantes B e A, primeiro e segundo colocados respectivamente, é relativamente pequena.

A partir dos questionários, foi possível perceber a homogeneidade dos entrevistados, sobretudo no que tange à formação acadêmica e o tempo de experiência das amostras obtidas, confirmando a proximidade dos resultados obtidos. Analisando o gráfico de Resultados por Critério (Figura 4), é possível perceber que nos sub-critérios relacionados a "Custos", o Fabricante C teve grande vantagem em relação aos outros fabricantes.

Figura 4 - Gráfico de Resultados por Critério

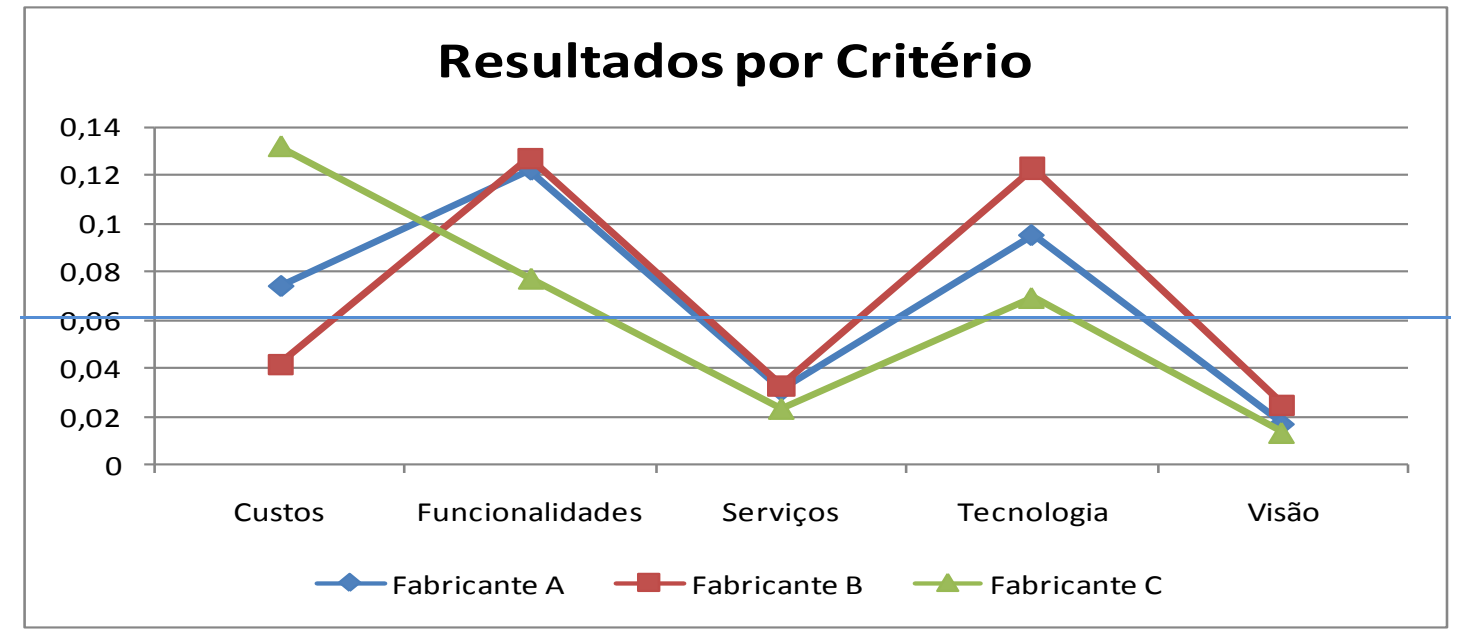

Santos e Campos (2011) salientam que um bom dimensionamento de recursos e uma proteção contra as oscilações de demanda são fatores que ajudam na gestão dos serviços de TI

Entretanto, o peso atribuído pelos especialistas a essa categoria era menor que os pesos atribuídos à Tecnologia e Funcionalidades. O gráfico de dispersão, constante na Figura 5, permite concluir que os dois critérios considerados mais importantes pelos especialistas entrevistados (Funcionalidades - Peso: 0,326 e Tecnologia - Peso: 0,287) somam cerca de $61 \%$ dentre os critérios do primeiro nível. A comparação pode ser percebida na Figura 4, que mostra que dentre esses critérios, o Fabricante B apresenta melhor desempenho. 
Figura 5 - Gráfico de Dispersão (Funcionalidades vs. Tecnologia)

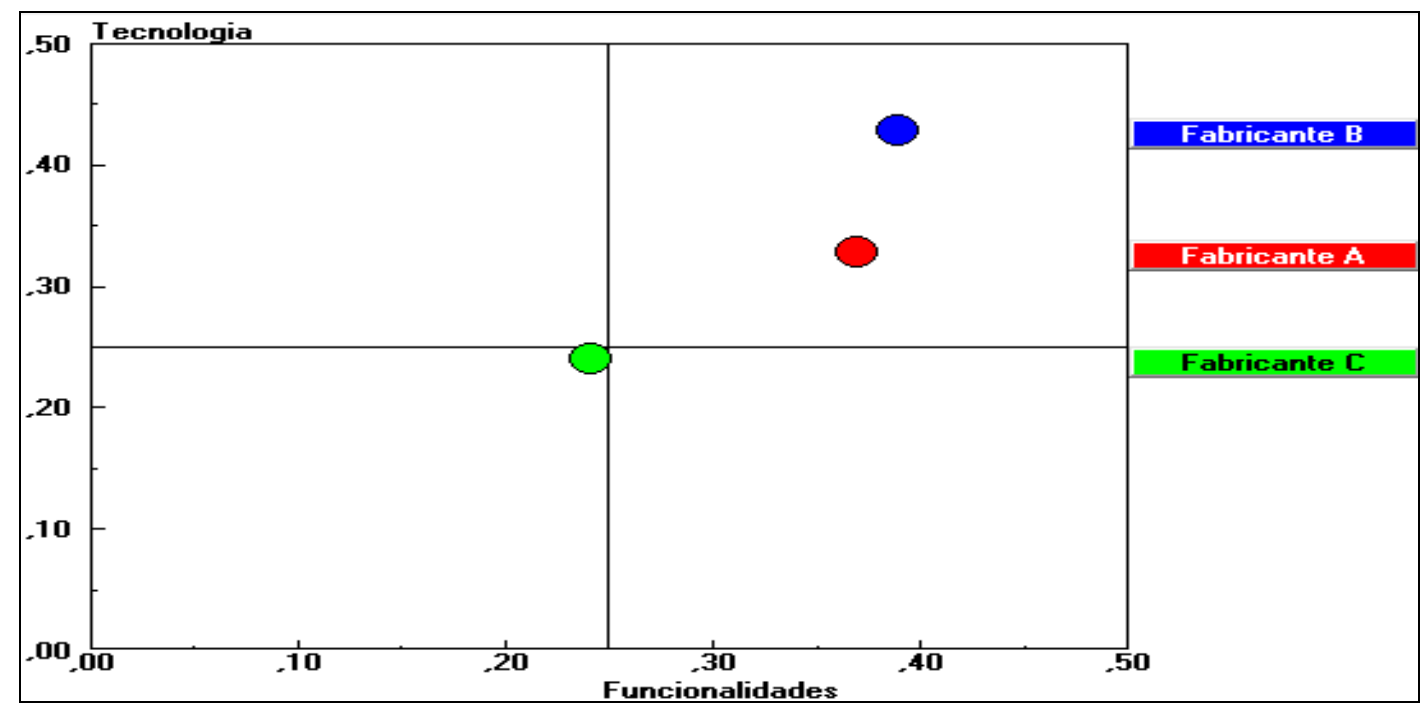

\subsection{Análise de Sensibilidade}

Equalizando os pesos dos critérios, foi possível perceber que não houve alteração na ordenação obtida feita a análise que contemplou os pesos atribuídos pelos especialistas.

Restaurando-se os pesos atribuídos pelos especialistas, podemos fazer outro tipo de análise: retirada das alternativas para verificar o impacto nas outras. A alternativa retirada será a que obteve menor pontuação, ou seja, o Fabricante C. Com isso, pôde-se perceber que após a retirada do Fabricante $C$, o Fabricante A obteve uma pontuação superior à obtida pelo Fabricante $B$, que era considerado o mais adequado pelos especialistas entre os três analisados anteriormente.

Pode-se afirmar também que o Fabricante $A$ é considerado melhor pelos especialistas quando diretamente comparado ao Fabricante B com os pesos escolhidos. Esse princípio é conhecido como "problema de inversão de ordem", sendo a maior crítica feita ao modelo AHP.

A próxima análise equalizará novamente os pesos dos critérios de avaliação e continuará com apenas duas alternativas. A análise nos mostra que para os entrevistados, o Fabricante $A$ é considerado ligeiramente superior ou muito parecido com o Fabricante $B$ quando os pesos estabelecidos na comparação são 
devidamente equalizados e balanceados. A pontuação final nesse caso passa para 0,501 - Fabricante A e 0,499 - Fabricante B.

Do gráfico representado na Figura 6 pode-se perceber que os especialistas consideram o Fabricante $A$ superior ao Fabricante $B$ em relação a Custos, porém Nos critérios de Tecnologia e Visão, o Fabricante B é considerado superior.

Figura 6 - Resultados por Critério (Análise de Sensibilidade)

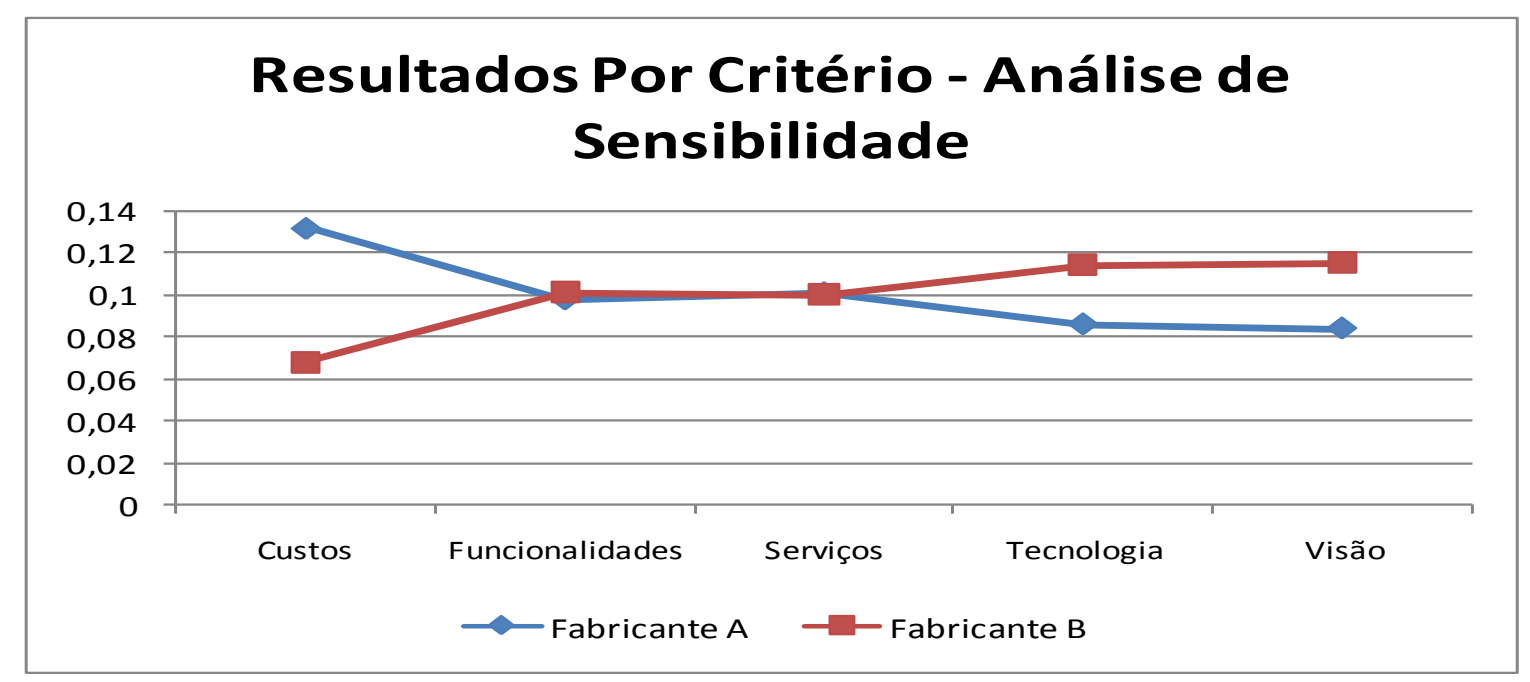

\section{CONCLUSÕES}

Entre as considerações tratadas nas pesquisas apresentadas, evidenciou-se que a visão holística e o uso de ferramentas de decisão adequadas são cruciais para um maior aproveitamento da solução final e menores danos financeiros e processuais às organizações. Entretanto, a pesquisa realizada teve cunho acadêmico, não podendo ser aproveitado diretamente por empresas pelos seguintes motivos:

a) Avaliação generalizada - Os avaliadores que responderam à pesquisa foram informados que deveriam analisar os critérios de acordo com suas visões acerca dos softwares, e neste caso as visões podem mudar de uma empresa para outra empresa de acordo com as necessidades e visões de cada empresa; 
b) Seleção de critérios - Os critérios selecionados foram analisados pelo autor utilizando-se de pesquisas sobre o tema. Na utilização em uma empresa diferente da citada, será necessário adequar à análise de critérios em relação às necessidades reais da nova empresa;

c) Peso dos critérios - Os critérios foram definidos pelos especialistas selecionados para a pesquisa, entretanto tais pesos serão diferentes em cada organização, por exemplo, uma empresa precisa de uma solução menos onerosa do que outra.

Outra crítica importante relacionado à pesquisa seria o questionamento da capacidade técnica dos especialistas. Para responder com grande certeza, o entrevistado precisa conhecer substancialmente todos os sistemas que serão analisados, o que acaba por ser um grande desafio para o pesquisador. Além disso, a reversão de ordem vem sendo muito criticada por alguns autores. Entretanto, esse problema pode ser resolvido com eventuais ajustes na modelagem dos critérios e subcritérios.

Sob a luz das teorias relacionadas à metodologia AHP, pode-se dizer que, com uma coleta de dados confiável é possível obter resultados confiáveis e resolver situações de forma organizada e com documentação relevante. Além disso, a metodologia possibilita um processo organizado e disciplinado, necessário para a tomada de decisão diminuindo a possibilidade de erros.

Destaca-se como contribuição obtida:

a) Identificação de um grande número de critérios que podem ser usados em processos de seleção de SIGE/ERP; estes mesmos critérios podem ser utilizados como benchamerketing em outros processos de aquisição de softwares.

b) A validação do uso do AMD neste processo.

Como trabalhos futuros identificam-se:

a) Aplicação do processo em outras empresas;

b) Aplicação do processo na ordenação de alternativas em outras aquisições no setor de $\mathrm{TI}$.

c) Utilização de outros métodos do AMD nestes processos de ordenação. 


\section{REFERÊNCIAS}

BAZERMAN, M. H.Processo decisório para cursos de administração e economia. Rio de Janeiro: Elsevier, 348p. 2004.

BELLI, C. Sistemas de gestão têm forte avanço. Disponível em:

$<$ http://valoronline.com.br/?impresso/comunicacao_de_valor/267/5789532/sistemasde-gestao-tem-forte-avanco>. Acesso em: 18 mar. 2010.

BELTON, Valerie; GEAR, Anthony E. On a short-coming of saaty's method of analytic hierarchies. Omega, v. 11, n. 3, p. 226-230, 1982

BELTON, V., STEWART, T.J. Multiple criteria decision analysis: an integrated approach. Massachusetts: Kluwer Academic Publishers, 2004.

BENÍTEZ, J.; DELGADO-GALVÁN, X.; IZQUIERDO, J.; PÉREZ-GARCÍA, R., Improving consistency in AHP decision-making processes Applied Mathematics and Computation, v.219, n. 5, p.2432-2441, nov. 2012.

BOUYSSOU, D. Some remarks on the notion of compensation in MCDM. European Journal of Operational Research, v.26, n.1, p.150-160. 1986.

BRODBECK, A. F. Alinhamento estratégico entre os planos de negócio e de tecnologia de informação: um modelo operacional para a implementação.

Disponível em: <http://hdl.handle.net/10183/1792>. Acesso em: 11 mar. 2010.

BUCKHOUT, S.; FREY, E.; NEMEC JR., J. Por um ERP eficaz. HSM Management, p. 30-36, set./ out. 1999.

CENTOLA, N.; ZABEU, S. B. Pequenas e médias empresas: tomem a rédea de seus negócios! PC WORLD, p. 34-54, mar. 1999.

COLANGELO, L. Implantação de sistemas ERP: um enfoque de longo prazo. Atlas, 2001.

COMERLATO, L., COSTA, C. A., LUCIANO, M. A. Avaliação de capacidade tecnológica de fornecedores para apoio ao desenvolvimento de produtos: estudo de caso em uma montadora de ônibus. Revista Produção Online, Florianópolis, SC, v.13, n. 2, p. 577-600, abr./jun. 2013.

CORREAA, H. C.; GIANESI, I.; CAON, M. Planejamento, programação e controle da produção: MRP II/ERP: conceitos, uso e implantação. São Paulo: Atlas, 1997.

COSTA, Helder Gomes . Auxílio multricritério à decisão: método AHP. 1. ed. Rio de Janeiro: Abepro, 2006. 
CUNHA, M. A. L. Gestão integrada de processos de negócio. SIMPÓSIO DE ADMINISTRAÇÃO DA PRODUÇÃO, LOGÍSTICA E OPERAÇÕES INDUSTRIAIS. Anais... São Paulo: FGV, 1998. p. 184-194.

DA COSTA, M. L., SOUZA, J. M., OKAMOTO, M. Avaliação do retorno sobre investimento em projetos de implantação de sistemas ERP. Disponível em <http://cronos.cos.ufrj.br/publicacoes/reltec/es65704.pdf> Acesso em: 14 abr. 2010.

DAVENPORT, T. H. Putting de enterprise into the enterprise system. Harvard Business Review, p.1221-1231, jul./ago. 1998.

DELOITTE CONSULTING. ERP's second wave: maximizing the value of ERP_Enabled Processes. Relatório de pesquisa publicado pela Deloitte Consulting. Disponível em: <http://www.dc.com/whathsnew/second.html>. Acesso em: 1998.

DEMPSEY, M. Pacote de ERP não resolve tudo. Gazeta Mercantil. Acesso em: 1999.

DIAS, M..F.P, FERNSTENSEIFER, J., SELLITTO, M.A., Análise multicriterial em estratégia de operações: estudo de caso com compradores de arroz de seis redes supermercadistas. Revista Produção On-line, v.11, n. 3, 2011.

DUARTE, Marina Dantas de Oliveira, GUSMÃO ,Ana Paula Henriques de, ALMEIDA, Adiel Teixeira de. Sistema de apoio a decisão com modelo aditivo para priorização de sistemas de informação. Revista Produção Online, v.5, n.4, 2005.

FARBEY, B ., LAND, F., TARGETT, D., Evaluating investments in IT. Journal of Information Technology, 7, p . 109-122, 1992

FIGUEIRA, José R., GRECO, S., EHRGOTT, Matthias. Multiple criteria decision analysis: state of the art surveys. New York: Springer, 2005.1045p.

FILHO, Jaime André Ramos; ATAMANCZUK, Mauricio João; MARÇAL, Rui Francisco Martins. Seleção de técnicas de manutenção para processo de armazenagem pelo método de análise hierárquica. Revista Produção Online, v.10, n.1, p. 142-166, mar. De 2010. Disponível em $<$ http://www.producaoonline.org.br/index.php/rpo/article/view/375>.

GATTIKER, T. F. Enterprise resource planning (ERP) systems and the manufacturing-marketing interface: an information-processing theory view International Journal of Production Research, v. 45, n. 13, p. 2985-2917, 2007.

GOMES, C.F.S., RIBEIRO, P.C.C. Gestão da cadeia de suprimentos integrada a tecnologia da informação. 2.ed. São Paulo: Thomson Learning, 2013.

GOMES, C. F. S.; MENAHEM, D. G.. Estudo de caso de um novo entrante. no mercado brasileiro de perfurações de petróleo. Aquila. Rio de Janeiro, v. 8, p. 111126, 2012. 
GOMES, C.F.S, MAIA, A. C. C. Biomassa como alternativa para o fornecimento de energia. Pesquisa Operacional para o Desenvolvimento, v.4, n.1, 2012.

GOMES, L.F.A.M., GOMES, C.F.S. Tomada de decisão gerencial: enfoque multicritério. 4.ed. São Paulo: Atlas, 2012.

GÜRBÜZ, Tuncay ; ALPTEKIN, S. Emre ; IŞIKLAR Alptekin, Gülfem, A hybrid MCDM methodology for ERP selection problem with interacting criteria. Decision Support Systems, v. 54, n. 1, p.206-214, Dec. 2012.

HADDAD, R.B.B, CARVALHO, M., ROCHA, R. Integração entre erp e programação matemática um estudo de caso na indústria de autopeças. Revista Produção Online, v.4, n. 1, 2004.

HEHN, H. F. Peopleware: como trabalhar o fator humano na implementação de sistemas integrados de informação (ERP). São Paulo: Editora Gente, 1999.

LIMA, A. Implantação de pacote de gestão empresarial em médias empresas. 2000. Disponível em: <http://www.kmpress.com.br>. Acesso em: 1 maio 2010.

MENDES, J. V., FILHO, E. E. Sistemas Integrados de Gestão ERP em pequenas empresas: um confronto entre o referencial teórico e a prática empresarial. Gestão \& Produção, v. 9, n. 3, p. 277-296, dez. 2002.

MILTELLO, K. Quem precisa de um ERP? Info Exame, p. 140, mar. 1999.

MIRANDA, C.M.G. et al. Sistema de apoio a decisão para seleção de atividades críticas no gerenciamento de projetos com avaliação multicritério. Revista Produção On-line, v. 3, n. 4, abr. 2003.

PORTAL do ERP. Disponível em: <http://sistemaerp.org/>. Acesso em nov. 2012.

RAMOS, P.R, Avaliação do desempenho de candidatos à outorga de uso da água para abastecimento humano: estudo de caso da bacia do Rio Cubatão do Sul.

Revista Produção On-line, v.7, n.1, abr. 2007.

RIBEIRO, R., RIBEIRO, A. Análise dos fatores críticos de sucesso da implantação de sistemas erp através da modelagem por equações estruturais. SIGE/ITA.

Anais... 2004.

SAATY, T. L. Decision making with the analytic hierarchy process. Disponível em: <http://www.colorado.edu/geography/leyk/geog_5113/readings/saaty_2008.pdf>. Acesso em: 15 mar. 2010a.

SAATY, T. L. How to make a decision: the analytic hierarchy process. Disponível em: <http://dunamis.ce.berkeley.edu/rebar/resources/workshop7/Saaty 
\%201990\%20How\%20to\%20Make\%20a\%20Decision.pdf>. Acesso em: 15 mar. $2010 \mathrm{~b}$.

SAATY, T.L., SHANG, J.S. Group decision-making: Head-count versus intensity of preference. Socio-Economic Planning Sciences, v.41, n. 1, p.22-37, Mar. 2007.

SACCOL, Amarolinda Zanela et al. Avaliação do impacto dos sistemas ERP sobre variáveis estratégicas de grandes empresas no Brasil. RAC, v.8, n. 1, p. 9-34, mar. 2004.

SANTOS, G.S.; CAMPOS, F.C., Operação de serviços de TI: uma abordagem do dimensionamento de recursos e dos incentivos financeiros. Revista Produção Online, v. 11, n. 4, 2011.

SOUZA, Joana Siqueira de; NETO, Francisco José Kliemann; FILOMENA, Tiago Pascoal. Definição de portfólio de investimentos em uma empresa usando análise multicriterial. Revista Produção Online, v.10, n.1, p. 166-197, mar. 2010. Disponível em:

<http://www.producaoonline.org.br/index.php/rpo/article/view/409>.

STAMFORD, P. P. ERPs: prepare-se para esta mudança. KMPress, jun. 2000. Disponível em: <http://www.kmpress.com.br/00set 02.htm>.

VANDERLEI M.L. et al. Implantação de controle baseado no sistema de execução da manufatura (mes): análise em empresa de usinagem no setor aeronáutico Revista Produção on-line, v.9, n. 4, 2009.

WOOD JR., T. Modas e modismos gerenciais: o caso dos sistemas integrados de gestão. Série de Relatórios de Pesquisa, NPP, Núcleo de Pesquisas e Publicações. Escola de Administração de Empresas de São Paulo, FGV. Relatório n. 16/ 1999.

ZWICKER, R. Implementação de sistemas ERP: um estudo de casos comparados. In: ENCONTRO ANUAL DA ANPAD, 24., 2000, Florianópolis. Anais... Florianópolis: ANPAD, 2000.

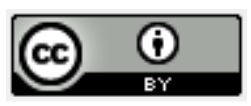

Artigo recebido em 15/07/2012 e aceito para publicação em 27/07/2013. 